\title{
Loading and promoter effects on the performance of nitrogen functionalized graphene nanosheets supported cobalt Fischer-Tropsch synthesis catalysts
}

\author{
Somayeh Taghavi ${ }^{a, b, c, *}$, Ahmad Tavasoli ${ }^{a}$, Alireza Asghari ${ }^{b}$, \\ Michela Signoretto ${ }^{c}$ \\ a School of Chemistry, College of Science, University of Tehran, Tehran, Iran \\ b Department of Chemistry, Semnan University, Semnan, Iran \\ c CATMAT Lab, Department of Molecular Sciences and Nanosystems, Ca' Foscari University Venice and INSTM \\ Consortium, RU of Venice, Via Torino 155, 30172 Venezia Mestre, Italy
}

\section{A R T I C L E I N F O}

Article history:

Received 6 November 2018

Received in revised form

25 February 2019

Accepted 1 March 2019

Available online $\mathrm{xxx}$

Keywords:

Fischer-tropsch synthesis

Cobalt

Ruthenium

Functionalized graphene

Activity

Selectivity

\begin{abstract}
A B S T R A C T
The effects of nitrogen functional groups on graphene surface and also the effects of cobalt loading and ruthenium promoter on the performance of nitrogen functionalized graphene nanosheets (N-GNS) supported cobalt catalysts in Fischer-Tropsch synthesis (FTS) are investigated. A $15 \mathrm{wt} \% \mathrm{Co} / \mathrm{PGNS}$ catalyst, a series of Co/N-GNS (15-30 wt\% loading) and ruthenium promoted catalysts (25 wt\% Co,0.5 wt\% Ru/N-GNS and 25 wt\% Co,0.5 wt\% Ru/ PGNS) were prepared by impregnation method. The purified GNS and functionalized GNS and all catalysts were characterized by Raman spectroscopy, FTIR, SEM, EDS, ICP, BET, TEM, XRD and TPR. The catalysts assessed in FTS in a fixed bed micro-reactor at $220^{\circ} \mathrm{C}, 1.8$ $\mathrm{Mpa}$ and $\mathrm{H}_{2} / \mathrm{CO}$ ratio of 2. Functionalization of GNS shifted the TPR reduction peaks to lower temperature, increased the dispersion of cobalt particles and increased the percentage $\mathrm{CO}$ conversion from $70.6 \%$ to $74.5 \%$. Increasing the cobalt loading resulted in increasing the average cobalt cluster size, improvements in the reducibility of $\mathrm{Co}_{3} \mathrm{O}_{4}$. The maximum FTS activity for N-GNS supported catalyst is achieved at $30 \mathrm{wt} \%$ cobalt loading. The $\mathrm{C}_{5}^{+}$selectivity for the $30 \mathrm{wt} \%$ cobalt catalyst was higher than that of the $15 \mathrm{wt} \%$ Cobalt catalyst. Addition of $0.5 \mathrm{wt} \% \mathrm{Ru}$ increased the FTS rate (gCH/(gcat.h)) from 0.377 to 0.412 and the liquid products selectivity from $86.5 \%$ to $91.2 \%$.
\end{abstract}

(c) 2019 Hydrogen Energy Publications LLC. Published by Elsevier Ltd. All rights reserved.

\section{Introduction}

Fischer-Tropsch synthesis (FTS) is a catalytic polymerization reaction producing a vast range of hydrocarbons from syngas
$\left(\mathrm{H}_{2}\right.$ and $\left.\mathrm{CO}\right)$ derived from natural gas. This reaction could be a promising process for the production of clean liquid fuels. Nowadays, development of this technology can be ascribed to some economic and socio-political causes related to the crude oil. However, there are some challenges for production of

\footnotetext{
* Corresponding author. CATMAT Lab, Department of Molecular Sciences and Nanosystems, Ca' Foscari University Venice and INSTM Consortium, RU of Venice, Via Torino 155, 30172 Venezia Mestre, Italy.
}

E-mail address: s.taghavi67@alumni.ut.ac.ir (S. Taghavi). 
syngas from different resources. Thus, syngas feed produced from coal and biomass resources have either a shortage in $\mathrm{H}_{2}$ or excess in $\mathrm{CO}$ and could influence the optimal $\mathrm{H}_{2} / \mathrm{CO}$ ratio required. Therefore, the importance of this fact should be considered [1].

Supported cobalt catalysts are preferred for gas to liquid reaction (GTL) because of their high activity, high stability and high selectivity to longer hydrocarbons [2,3]. Nobel metals such as ruthenium have been reported as a promoter for cobalt catalysts supported on $\mathrm{Al}_{2} \mathrm{O}_{3}, \mathrm{SiO}_{2}, \mathrm{TiO}_{2}$, and CNTs. It has been shown that ruthenium can promote cobalt catalyst by decreasing the reduction temperature of the cobalt oxides and increasing the dispersion of cobalt clusters. Furthermore, ruthenium not only increases the number of active surface cobalt sites $\left(\mathrm{Co}^{\circ}\right)$ for FTS reaction but also enhances the $\mathrm{CO}$ conversion and FTS reaction rate. Ruthenium is more selective toward higher molecular weight hydrocarbons than cobalt $[4,5]$.

Up to now, most researchers have used alumina, silica, titania as a support for FTS reaction catalysts. Nowadays, a new group of supports with carbonaceous bases such as activated carbon, carbon nanotubes (CNTs) and graphene nanosheet (GNS) have also been investigated [6,7]. As a support for FTS catalyst, GNS has some unique advantages including properties of two-dimensional structure, great intrinsic carrier, well-developed porosity, high active surface area, outstanding electronic properties and promising mechanical and thermal stability [8]. There is a common and effective method to convert hydrophobic GNS into a hydrophilic substance with surface functionalization of GNS [9]. Therefore, surface functional groups allow using the polar solvent during the synthesis of metal catalysts. Functionalization of GNS improves the metal-support interaction and stability of the catalysts in different reactions $[10,11]$.

In the present work, graphene was functionalized with nitrogen functional groups before loading of cobalt precursors. Then, a series of a $15 \mathrm{wt} \% \mathrm{Co} / \mathrm{PGNS}\left(\mathrm{C}_{1}\right),(15-30 \mathrm{wt}$ \%) Co/N-GNS $\left(\mathrm{C}_{2}-\mathrm{C}_{5}\right), 25 \mathrm{wt} \%$ Co,0.5 wt\% Ru/N-GNS $\left(\mathrm{C}_{6}\right)$ and $25 \mathrm{wt} \%$ Co,0.5 wt\% Ru/PGNS $\left(\mathrm{C}_{7}\right)$ catalyst were prepared by impregnation method. The $C_{1}$ and $C_{2}$ catalysts are related to our previous results [12]. All catalysts were characterized by ICP, BET, XRD, TPR, and TEM and assessed in FTS reaction in a fixed bed microreactor at $220^{\circ} \mathrm{C}$ and 1.8 Mpa.

\section{Experimental}

\section{Support preparation}

Preparation and purification of graphene

Purified and functionalized graphene were used as the support for preparation of cobalt catalysts. The graphene (GNS) was synthesized in Research Institute of Petroleum Industry, Tehran, Iran. For removal of graphene impurities, the support was refluxed in $30 \% \mathrm{HNO}_{3}$ at $120{ }^{\circ} \mathrm{C}$ overnight, washed with distilled water several times and dried at $120^{\circ} \mathrm{C}$ for $6 \mathrm{~h}$. For the sake of elimination of the amorphous carbons, the temperature was increased to $400{ }^{\circ} \mathrm{C}$ in the air with a ramp rate of $10^{\circ} \mathrm{C} / \mathrm{min}$ and kept up at this temperature for $20 \mathrm{~min}$ [13]. This support was named PGNS.

\section{Functionalization of graphene}

It is known that graphene has a hydrophobic nature, which causes agglomeration and precipitation in water in the absence of a dispersant/surfactant. Up to now, many methods have been published for chemical functionalization of graphene and preparing hydrophilic graphene. Among them, we choose one method for functionalization of graphene with $\mathrm{N}$ containing functional groups. For this aim, graphene was treated at $400{ }^{\circ} \mathrm{C}$ for $6 \mathrm{~h}$ in flowing ammonia with a flow rate of $25 \mathrm{sccm}$ (10 vol\% $\mathrm{NH}_{3}$ in $\mathrm{He}$ ). The ammonia gas was neutralized by importing to acetic acid solution. This support was named N-GNS.

\section{Catalyst preparation}

Purified graphene nanosheet (PGNS) and functionalized graphene nanosheet (N-GNS) were used as support for the preparation of catalysts. PGNS supported catalyst $\left(C_{1}\right)$ with cobalt loading of $15 \mathrm{wt} \%, \mathrm{~N}-\mathrm{GNS}$ supported catalysts $\left(\mathrm{C}_{2}-\mathrm{C}_{5}\right)$ with cobalt loadings of $15,20,25,30 \%$ and N-GNS and PGNS supported catalysts $\left(\mathrm{C}_{6}\right.$ and $\left.\mathrm{C}_{7}\right)$ with loading of $25 \mathrm{wt} \%$ cobalt and 0.5 wt\% ruthenium were prepared by impregnation technique with aqueous solutions of cobalt nitrate $(\mathrm{Co}(\mathrm{N}-$ $\left.\mathrm{O}_{3}\right)_{2} \cdot 6 \mathrm{H}_{2} \mathrm{O}, 99 \%$, Merck) and ruthenium nitrosyl nitrate $(\mathrm{Ru}(\mathrm{N}-$ O) $\left(\mathrm{NO}_{3}\right)_{3}$, Aldrich). After the impregnation step, the catalysts were dried at $120^{\circ} \mathrm{C}$ and calcined at $400^{\circ} \mathrm{C}$ under argon flow for $3 \mathrm{~h}$ with a heating rate of $10^{\circ} \mathrm{C} / \mathrm{min}$. The samples were carefully passivated at $150{ }^{\circ} \mathrm{C}$ using 1:200 (v/v) flow of $\mathrm{O}_{2} / \mathrm{Ar}$ gas mixture, during the cooling step.

\section{Characterization}

The FTIR absorption technique for confirming the formation of functional groups was conducted on a Bruker ISS-88. A smooth transparent pellet of $0.5-5 \%$ of GNS mixed with 95-99.5\% potassium bromide $(\mathrm{KBr})$, was made and the infrared beam passed through this pellet.

The Raman shift of the support material was measured on a Confocal Raman Microscope Systems with a laser source of $785 \mathrm{~nm}$.

The metal loadings of the calcined catalysts were performed using Varian VISTA-MPX inductively coupled plasmaoptical emission spectrometry (ICP-OES) instrument (Varian Medical Systems, Inc., Palo Alto, CA, USA). For this purpose, $0.02 \mathrm{~g}$ of sample was dispersed in $5 \mathrm{ml}$ of nitric acid (Merck $65 \%$ ) and $5 \mathrm{ml}$ hydrochloric acid (Chem-Lab, 37\%). The temperature of the mixture was kept at $40-50{ }^{\circ} \mathrm{C}$ for $2 \mathrm{~h}$. The resulting mixture was filtered and washed several times with distilled water. The filtrate solution was diluted with deionized water up to $250 \mathrm{ml}$ (acid digestion).

The surface area, pore volume, and average pore radius of the support and catalysts were measured by a MICROMERITICS ASAP 2000 analyzer. The samples were degassed at $300{ }^{\circ} \mathrm{C}$ for $2 \mathrm{~h}$ under $50 \mathrm{mTorr}$ vacuum and their BET area, pore volume, and average pore radius were determined.

TEM microscopy was carried out using a Philips CM20 $(100 \mathrm{kV})$ transmission electron microscope. The samples were 
prepared by putting one drop of an ethanol dispersion of the catalysts on a copper grid pre-coated with a Formvar film and dried in air. FE-SEM images were obtained using a Field Emission Gun Electron Scanning Microscopy LEO 1525 ZEISS, after metallization with Chromium. The images were acquired by InLens detector while elemental composition was determined using Bruker Quantax EDS.

X-Ray Diffraction (XRD) patterns of the samples were collected employing a Bruker D8 Advance powder diffractometer with a sealed X-ray tube (copper anode; operating conditions, $40 \mathrm{kV}$ and $40 \mathrm{~mA}$ ) and a $\mathrm{Si}$ (Li) solid state detector (Sol-X) set to discriminate the $\mathrm{Cu} \mathrm{K} \alpha$ radiation. Apertures of divergence, receiving and detector slits were $2.0 \mathrm{~mm}$, $2.0 \mathrm{~mm}$, and $0.2 \mathrm{~mm}$ respectively. Data scans were performed in the $2 \theta$ range of $5-75^{\circ}$ with $0.02^{\circ}$ step size and counting times of $3 \mathrm{~s} / \mathrm{step}$. Quantitative phase analysis and crystallite size determination were performed by the Rietveld method as implemented in the TOPAS v.4 program (Bruker AXS) using the fundamental parameters approach for line-profile fitting. The determination of crystallite size was accomplished by the Double-Voigt approach and calculated as volume-weighted mean column heights based on integral breadths of peaks.

The $\mathrm{H}_{2}$-TPR profiles of the catalysts were performed in a lab-made equipment in order to study the reducibility of the metal species in the catalysts. The calcined catalyst sample $(0.05 \mathrm{~g})$ was first purged in a flow of Helium at $140{ }^{\circ} \mathrm{C}$ to remove traces of water and gasses exist in the catalyst and then cooled to $40{ }^{\circ} \mathrm{C}$. Then, the temperature-programmed reduction (TPR) of each sample was performed using $5 \% \mathrm{H}_{2}$ in Ar stream at a flow rate of $40 \mathrm{ml} / \mathrm{min}$ at atmospheric pressure using Micrometrics TPD-TPR 2900 analyzer equipped with a thermal conductivity detector (TCD), heating at a linearly programmed rate of $10^{\circ} \mathrm{C} / \mathrm{min}$ up to $850^{\circ} \mathrm{C}$.

\section{Reaction testing and experimental outline}

A tubular down flow, fixed-bed reactor system (Fig. 1) was used to investigate the performance of catalysts for the FTS. The Reactor temperature was controlled with a PID temperature controller. Two mass flow controllers (Brooks, Model 5850) were used to control the flow rate of the inlet gas $\left(\mathrm{CO}, \mathrm{H}_{2}\right) .0 .7 \mathrm{~g}$ of catalyst powder $(400-500 \mu)$ was diluted with $2.1 \mathrm{~g}$ of 90 mesh $\mathrm{SiC}$ to eliminate temperature gradient and then the mixture was loaded in the reactor (stainless steel tube of $450-\mathrm{mm}$ length and $22-\mathrm{mm}$ inside diameter). During the FTS reaction, catalysts were reduced at $400{ }^{\circ} \mathrm{C}$ in atmospheric pressure for $20 \mathrm{~h}$ by flowing pure hydrogen. FTS reaction was performed at $220^{\circ} \mathrm{C}, 1.8 \mathrm{Mpa}, \mathrm{H}_{2} / \mathrm{CO}$ ratio of 2 with a flow of $60 \mathrm{ml} / \mathrm{min}$. The liquid products from the reactor were separated into a hot $\left(100{ }^{\circ} \mathrm{C}\right)$ and cold trap $\left(0{ }^{\circ} \mathrm{C}\right)$ containers and were extracted every $12 \mathrm{~h}$. The $\mathrm{CO}, \mathrm{CO}_{2}$ and other gas products were overseen with time intervals of $2 \mathrm{~h}$. The outlet gases and liquid products are analyzed using gas chromatography.

With the GC analyses results, Carbon conversion was measured from the difference of inlet and outlet CO moles according to the following equation.

CO conversion (\% by moles):

$X_{\mathrm{CO}}(\%)=\frac{(\text { Moles of CO at inlet })-(\text { Moles of CO at outlet })}{(\text { Moles of CO at inlet })} \times 100$

$\mathrm{CO}_{2}$ selectivity was determined from Eq. (2) and Carbon selectivities were calculated using Eqs. (3) and (4). $\mathrm{C}_{5}^{+}$selectivity was calculated from the difference between the overall conversion of $\mathrm{CO}$ determined from Eq. (1) and the selectivity of $\mathrm{C}_{1}$ to $\mathrm{C}_{4}$ products, all of which are in the gas phase.

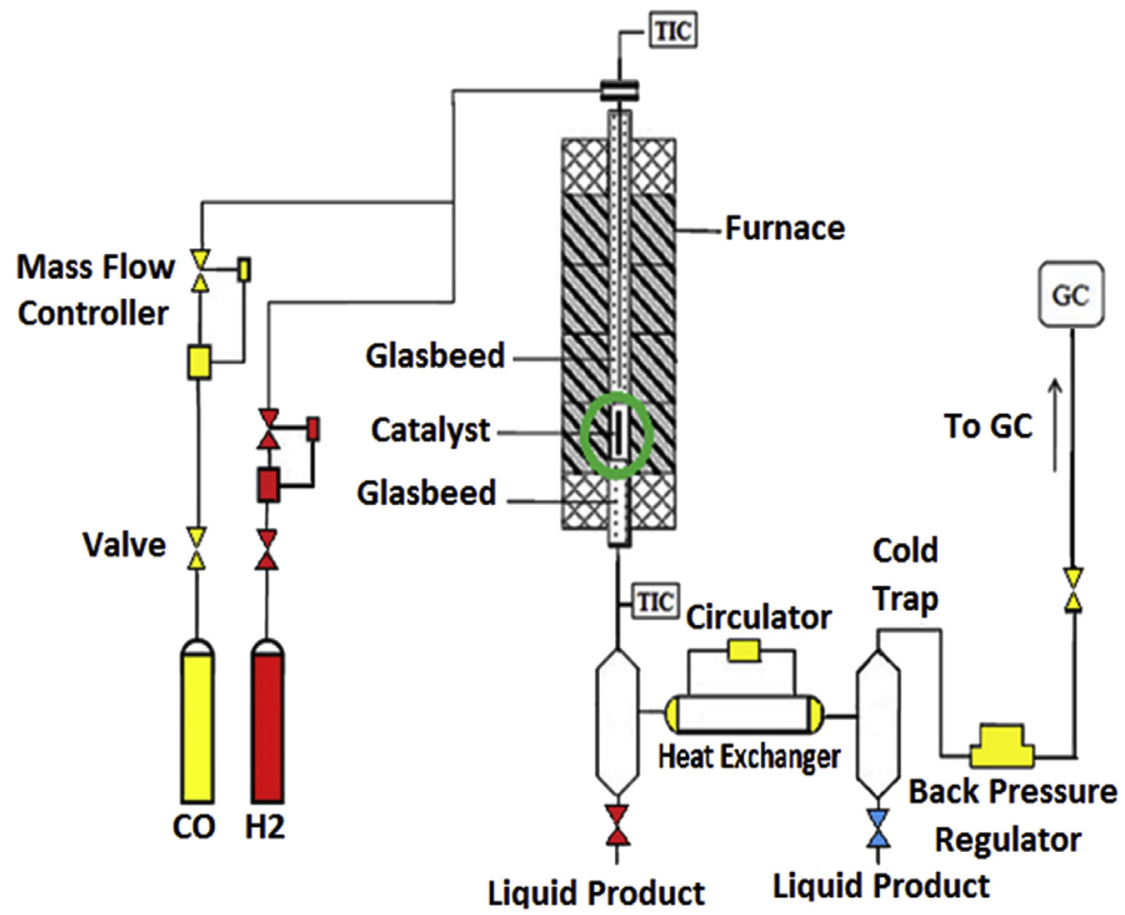

Fig. 1 - Catalyst test system. 
$\mathrm{CO}_{2}$ selectivity (\% by moles):

$$
\begin{aligned}
\mathrm{X}_{\mathrm{CO}_{2}}(\%)= & \frac{\left(\text { Moles of } \mathrm{CO}_{2} \text { at outlet }\right)}{(\text { Moles of CO at inlet })-(\text { Moles of } \mathrm{CO} \text { at outlet })} \\
& \times 100
\end{aligned}
$$

$\mathrm{C}_{\mathrm{n}}$ selectivity (\% by C-atoms):

$S_{C_{n}}(\%)=\frac{n_{i} M_{i}}{\sum n_{i} M_{i}} \times 100$

where $n_{i}$ is the number of carbon atoms in product $i$ and $M_{i}$ is the percentage of product $\mathrm{i}$.

$\mathrm{C}_{5+}$ selectivity (\% by C-atoms) [14]:

$\mathrm{S}_{\mathrm{C}_{5+}}=100-\sum_{1}^{4} \mathrm{~S}_{\mathrm{C}_{n}}(\%)$

\section{Fischer-Tropsch reaction}

In the cobalt-based FTS, the oxygen from CO dissociation is almost completely discarded as water. The catalyst provides both FTS and water-gas-shift (WGS) reaction activities. The FTS and WGS reactions can be shown as:

Alkanes: $\mathrm{nCO}+(2 \mathrm{n}+1) \mathrm{H}_{2} \rightarrow \mathrm{C}_{n} \mathrm{H}_{2 n+2}+\mathrm{nH}_{2} \mathrm{O}$

WGS:

$$
\mathrm{CO}+\mathrm{H}_{2} \mathrm{O} \leftrightarrow \mathrm{CO}_{2}+\mathrm{H}_{2}
$$

The WGS reaction is a reversible parallel-consecutive reaction with respect to $\mathrm{CO}$ and assumed that carbon dioxide is essentially formed by this reaction [15].

Different mechanisms based on different intermediates were proposed to govern the FT syn-crude composition. Carbide mechanism supports the production of paraffin in FTS. As can be seen in Fig. 2, In a carbide mechanism, adsorption of carbon monoxide on the catalyst surface initiates the FTS.
Obtaining high surface area of catalysts in order to increase catalytic activity and selectivity is a main issue, and depends on particle size and appropriate distance between each particle. The major properties of GNS are their hydrophobic and inert nature. Poor interaction with the metal particles causes further agglomeration and sintering. Functionalization changes the hydrophobic GNS to hydrophilic GNS so that the GNS surface becomes more reactive. The presence of functional groups on GNS surface gives rise to cation-exchange properties which can act as anchoring sites for the metal particles. It seems that, formation of functional groups on GNS surface, not only decrease the sintering of cobalt, but also accelerate the hydrogen spill-over effect in the reduction process. This in turn will increase percentage dispersion, reduction degree, stability and performance of these catalysts simultaneously [12].

\section{Results and discussion}

\section{Graphene characterization}

FTIR spectrums of the PGNS and N-GNS are shown in Fig. 3. The absence of graphite and graphene oxide peaks is a strong indication of the obtaining graphene sheets. The peaks at around $1575 \mathrm{~cm}^{-1}$ and $1578 \mathrm{~cm}^{-1}$ are allocated to the $\mathrm{C}=\mathrm{C}$ bond vibrations of aromatic structures for PGNS and N-GNS which are in association with graphene. The peaks of $-\mathrm{OH}$ vibrations can be seen at around $3300-3600 \mathrm{~cm}^{-1}$. The presence of two peaks at $1790 \mathrm{~cm}^{-1}$ and $1165 \mathrm{~cm}^{-1}$ are assigned to the $\mathrm{C}=\mathrm{O}$ and $\mathrm{C}-\mathrm{O}$ stretching vibrations of carboxylic acid and carbonyl groups, respectively. The vibration of $\mathrm{C}-\mathrm{H}$ for alkene appears at $2850-2950 \mathrm{~cm}^{-1}$. There is a peak at $615 \mathrm{~cm}^{-1}$ bands of $\mathrm{C}-\mathrm{H}$ bending mode. The main reason for this peak is the defects which are formed when the graphene is significantly functionalized. The slender and distinct vibration peak at

(1)

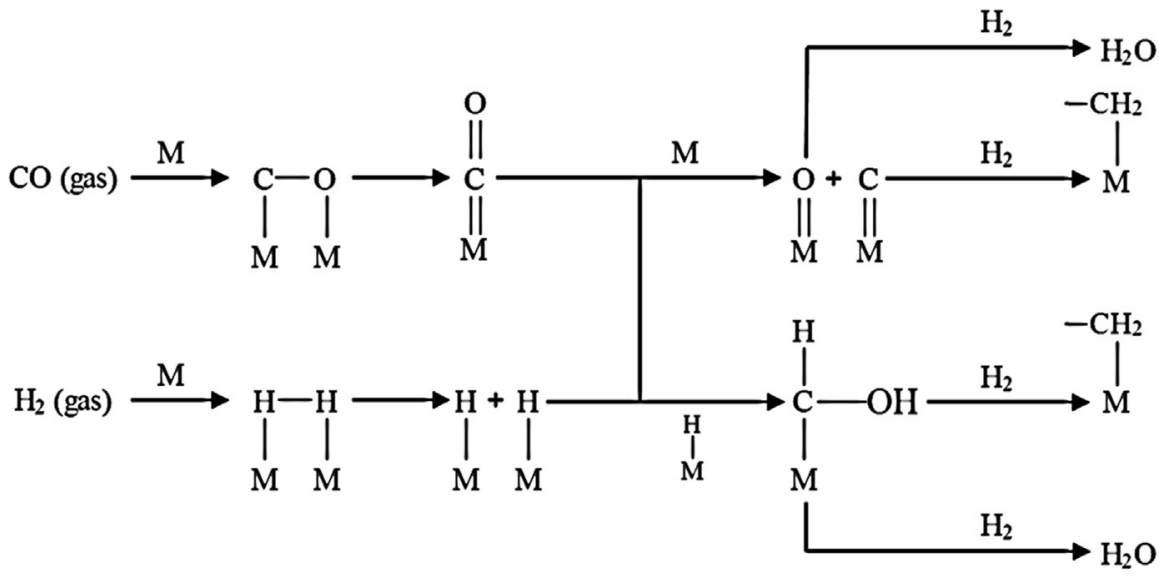

(2)

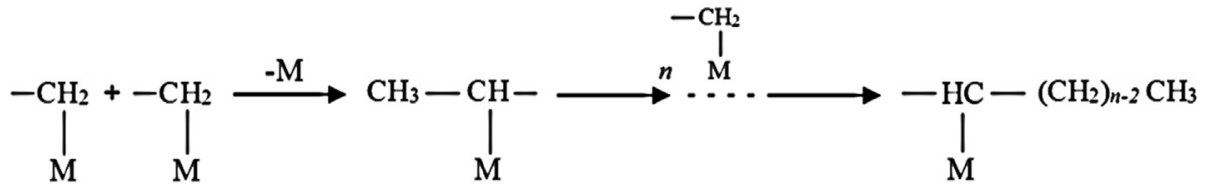

Fig. 2 - Carbide mechanism of FTS [16]. 


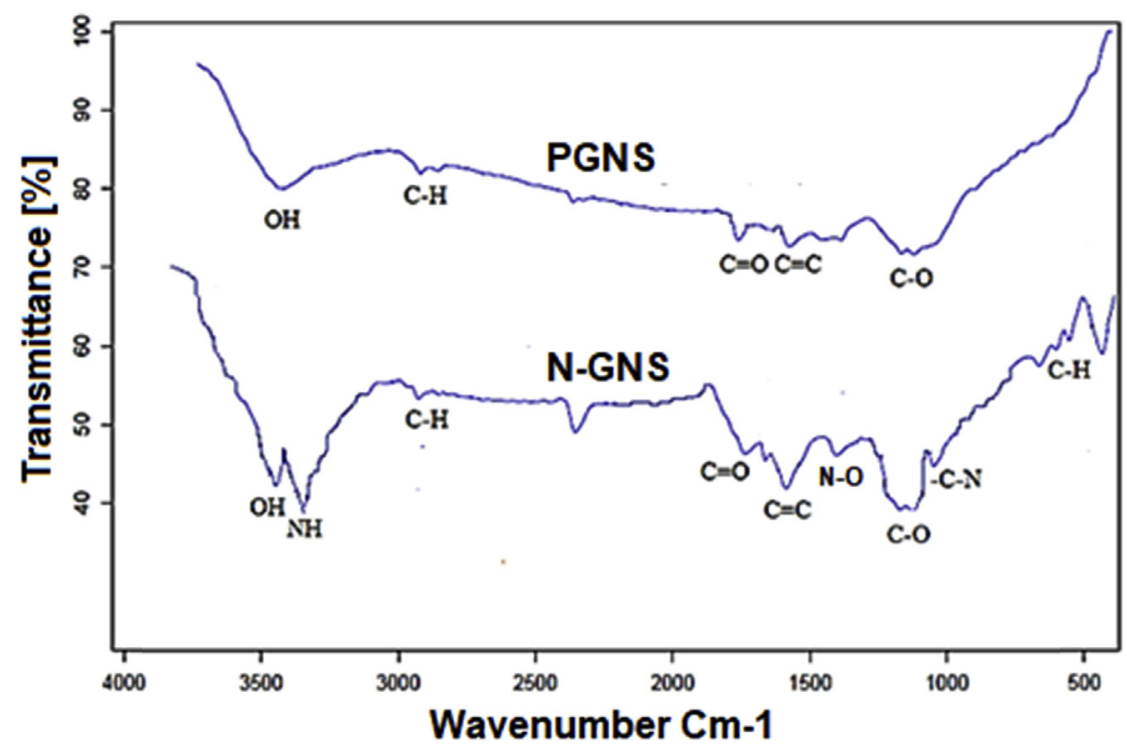

Fig. 3 - FTIR spectra of PGNS and N-GNS.

$1380 \mathrm{~cm}^{-1}$ stemmed from nitrogen group component $(\mathrm{N}-\mathrm{O})$ [17]. The peak at $1020 \mathrm{~cm}^{-1}$ can correspond to the $-\mathrm{C}-\mathrm{N}$ stretching frequency. The spectra show a large broad band at $3300-3400 \mathrm{~cm}^{-1}$ due to $-\mathrm{NH}$ stretching frequency [18].

Raman spectroscopy provides a sensitive tool for characterizing carbon materials in general and functionalized materials in particular. Raman spectra of purified and functionalized GNSs are illustrated in Fig. 4. Both supports exhibited peaks at 1348 and $1585 \mathrm{~cm}^{-1}$ correspond to the D and $\mathrm{G}$ bands of carbon, respectively. The D-band in a Raman spectrum, used as an indication of the presence of $\mathrm{sp}^{3}$ carbons which assigns to disordered or turbostratic structure of carbon materials, while the G peak is associated with the bond stretching of all $\mathrm{sp}^{2}$ carbon domains which assigns to the graphite-like structure [17]. Therefore, the ratio of the intensity of the $D$ band to that of the $G$ band (D/G) indicating the defect level or degree of disordered structure in graphene.

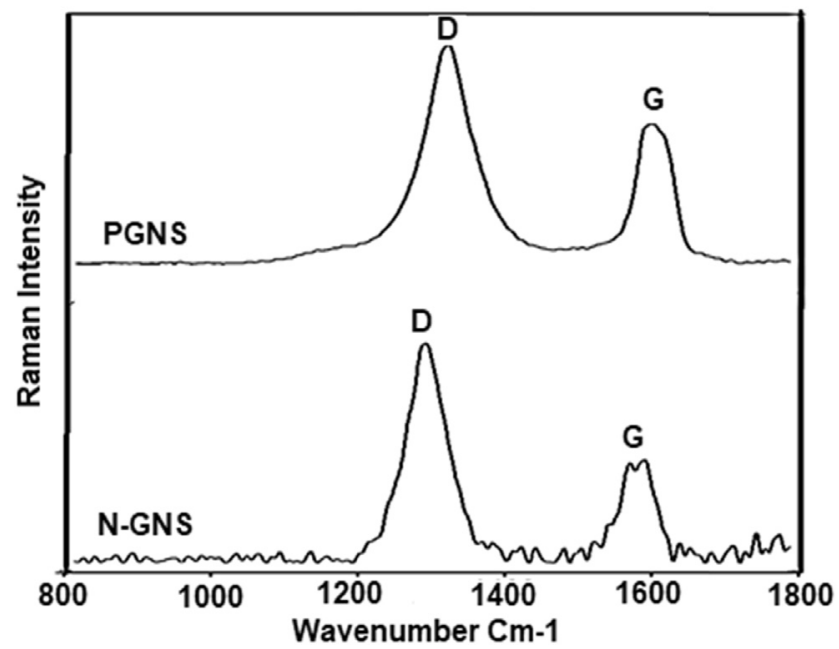

Fig. 4 - Raman spectra of PGNS and N-GNS.
This ratio approaches zero for highly ordered pyrolytic graphite [19]. The D/G ratios are 2.06 and 1.53 for $\mathrm{N}-\mathrm{GNS}$ and PGNS, respectively. The D/G ratios for $\mathrm{N}$-functionalized GNS is higher than that of purified GNS. Generally, there is an increase in the intensity of the D-band with functionalization [20]. So, we can reach the conclusion that functionalization of GNS increases the $\mathrm{sp}^{3}$ defect sites. The defects on the surface work as anchoring sites for stable metal particles on the support surface. The larger degree of disorder of the N-GNS than PGNS could be in association with the more defect sites for GNS with nitrogen functional group [14].

Fig. 5 shows the typical SEM images of PGNS and N-GNS. It can be seen that the supports consist of randomly crumpled and wrinkled sheets closely associated with each other and especially forming a disordered solid in N-GNS $[18,19]$.

In order to identify the functional elements distribution, EDS analysis was performed on PGNS and N-GNS and quantitative results are illustrated in Table 1 . As can be seen, the presence of oxygen in both PGNS and N-GNS is similar. In addition, N-GNS support contains $15.14 \mathrm{wt} \% \mathrm{Ni}$ trogen which indicates that further functionalized surface is available [21-23].

GNS is a hydrophobic support, which is inclined to aggregation and precipitation in water. The purified and functionalized graphene can disperse greatly in polar solvents because There are oxygen and nitrogen functional groups on the surface of GNS that can constitute a hydrogen bond with polar solvents which improve GNS dispersion in solution. Fig. 6 shows the dispersion and stability of GNS, PGNS and N-GNS in aqueous solutions after $48 \mathrm{~h}$ sonication. The common GNS settled down quickly in water, but the purified and functionalized GNS stayed as a well-dispersed solution for a number of days, without considerable change from their dispersion state. It was observed that dispersion of N-GNS sample was better and more stable than other samples. This behavior solidifies the FTIR spectrum and EDX results [24]. 

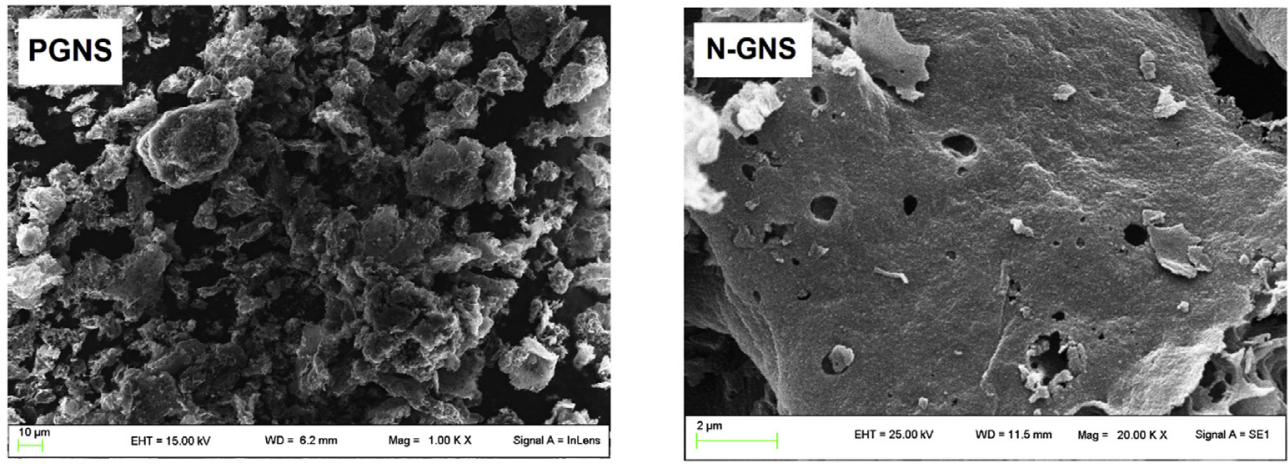

Fig. 5 - FESEM images of PGNS and N-GNS.

\section{Catalyst characterization}

Results of ICP, surface area measurement and textural properties of the supports and catalysts are listed in Table 2. ICP analyses show that the amount of metal in the catalysts was fairly close to the nominal Co metal content. According to BET results (Table 2), BET surface area for N-GNS is higher than that of PGNS (242 vs. $214 \mathrm{~m}^{2} / \mathrm{g}$ ). The discrepancy may be ascribed to the morphological changes of PGNS by defects which were formed when the graphene was significantly functionalized. Also, the table shows that the BET surface area of the N-GNS supported catalysts decreases by increasing the cobalt loading. These data indicate that pore blockage by cobalt oxide clusters is more in the case of the catalyst with higher metal content owing to larger cobalt particles of the catalyst. Due to low amounts of Ru (0.5 wt\%), the BET surface area, pore volume and average pore radius of the Ru promoted catalysts $\left(C_{6}\right)$ are very close to those of unpromoted $C_{4}$ catalyst.

Co nanoparticles dispersion for $C_{1}$ and $C_{2}$ catalysts was investigated by TEM. As shown in Fig. 7, Co nanoparticles are more uniform on the $\mathrm{C}_{2}$ catalyst and show better dispersion on the N-GNS surface and the Co particles size is approximately between 7.8 and $11.3 \mathrm{~nm}$. While, on the PGNS supported catalyst, the Co particles diameter is in the range of 9.8-18.4 $\mathrm{nm}$. Nitrogen functional groups and more defects on $\mathrm{N}-\mathrm{GNS}$ (according to Raman results) act as anchoring sites increasing the interaction between support and metal precursor and preventing metal particles agglomeration and sintering. This phenomenon leads to smaller particle size and better dispersion [25].

The XRD patterns of catalysts are indicated in Fig. 8. For all catalysts, the peaks at $2 \theta$ values of $25.0^{\circ}$ and $43.0^{\circ}$ correspond to graphene and confirms the existence of micropores in the structure of graphene [26], while the peaks at $2 \theta$ values of $31.3^{\circ}, 36.8^{\circ}, 56^{\circ}, 59.4^{\circ}$ and $65.3^{\circ}$ are associated with different

\section{Table 1 - EDX analyses of PGNS and N-GNS.}

\begin{tabular}{lccccc}
\multirow{2}{*}{ Element } & \multicolumn{2}{c}{ PGNS } & & \multicolumn{2}{c}{ N-GNS } \\
\cline { 2 - 3 } \cline { 5 - 6 } & Weight\% & Atomic\% & & Weight\% & Atomic\% \\
\hline C K & 83.99 & 88.20 & & 71.35 & 75.66 \\
O K & 16.01 & 11.80 & & 15.14 & 12.06 \\
N K & - & - & & 13.51 & 12.28 \\
\hline
\end{tabular}

crystal planes of $\mathrm{Co}_{3} \mathrm{O}_{4}$, the peaks at $2 \theta$ values of $44^{\circ}$ and $52^{\circ}$ are related to $\mathrm{CoO}$ and the peak at $2 \theta$ values of $75.8^{\circ}$ correspond to $\mathrm{Co}^{\circ}$. No peak was observed indicating formation of cobalt support compounds. The peak at $2 \theta$ value of $36.8^{\circ}$ is the most intense peak of $\mathrm{Co}_{3} \mathrm{O}_{4}$. Several studies specified that $\mathrm{Co}_{3} \mathrm{O}_{4}$ with spinel structure is the active phase and other peaks correlate with a cubic cobalt structure that has no effect on the catalyst performance [27]. From $C_{2}$ to $C_{5}$ catalysts the width of peaks become narrower. It can be seen that the increase of cobalt loading leads to higher crystallite size of $\mathrm{CO}_{3} \mathrm{O}_{4}$. Due to the introduction of low amount of $\mathrm{Ru}$ in the XRD pattern of $\mathrm{C}_{6}$ catalysts no peak is observed betokening diffraction lines of $\mathrm{Ru}$ oxide [28]. The mean $\mathrm{Co}_{3} \mathrm{O}_{4}$ crystallite sizes calculated by the Rietveld method at $2 \theta$ value of $36.8^{\circ}$ are presented in Table 2 [29]. As shown in the table, the average $\mathrm{Co}_{3} \mathrm{O}_{4}$ crystallite size in the $\mathrm{C}_{2}$ and $\mathrm{C}_{6}$ catalysts are smaller than that of $C_{1}$ and $C_{7}$ catalysts, respectively. Nitrogen functional groups on graphene enhance distribution of particles, which in turn leads to lower cobalt cluster sizes. For the unpromoted $\mathrm{C}_{2}-\mathrm{C}_{5}$ catalysts the average $\mathrm{Co}_{3} \mathrm{O}_{4}$ crystallite size showed a clear dependence on the cobalt loading. With the increase in cobalt loading from $C_{2}$ catalyst to $C_{5}$ catalyst, the cluster size enhanced as a result of an increase in agglomeration of cobalt particles. Table 2 also shows that the crystal diameter decreased marginally with the addition of $\mathrm{Ru}$. Due to the presence of novel metals during decomposition of cobalt nitrate complexes, the concentration of cobalt oxide crystallization sites was increased. Higher concentration of crystallization sites at the same cobalt content would lead to an

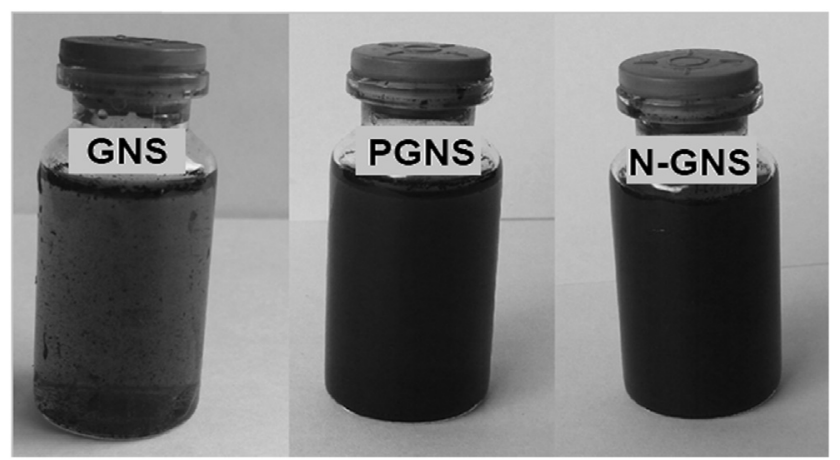

Fig. 6 - Dispersion photograph of GNS, PGNS and N-GNS after $48 \mathrm{~h}$. 
Table 2 - ICP, BET, Porosity and XRD data.

\begin{tabular}{|c|c|c|c|c|c|c|}
\hline Support/Catalyst & $\begin{array}{l}\text { Amount of } \\
\text { Co (wt.\%) }\end{array}$ & $\begin{array}{c}\text { Amount of } \\
\text { Ru (wt.\%) }\end{array}$ & $\begin{array}{c}\mathrm{S}_{\mathrm{BET}} \\
\left(\mathrm{m}^{2} / \mathrm{g}\right)\end{array}$ & $\begin{array}{c}\text { Pore volume } \\
\text { (single point) } \\
\left(\mathrm{cm}^{3} / \mathrm{g}\right)\end{array}$ & $\begin{array}{l}\text { Average Pore } \\
\text { radius }(\mathrm{nm})\end{array}$ & $\begin{array}{l}d_{\mathrm{XRD}} \\
(\mathrm{nm})\end{array}$ \\
\hline PGNS & - & - & 214 & 0.83 & 0.69 & - \\
\hline N-GNS & - & - & 242 & 0.87 & 0.63 & - \\
\hline 15Co/PGNS $\left(C_{1}\right)$ & 14.88 & - & 150 & 0.63 & 0.62 & 12.0 \\
\hline $15 \mathrm{Co} / \mathrm{N}-\mathrm{GNS}\left(\mathrm{C}_{2}\right)$ & 14.9 & - & 203 & 0.70 & 0.58 & 10.4 \\
\hline $20 \mathrm{Co} / \mathrm{N}-\mathrm{GNS}\left(\mathrm{C}_{3}\right)$ & 19.92 & - & 156 & 0.65 & 0.55 & 10.7 \\
\hline $25 \mathrm{Co} / \mathrm{N}-\mathrm{GNS}\left(\mathrm{C}_{4}\right)$ & 24.89 & - & 139 & 0.61 & 0.53 & 11.3 \\
\hline $30 \mathrm{Co} / \mathrm{N}-\mathrm{GNS}\left(\mathrm{C}_{5}\right)$ & 29.93 & - & 125 & 0.58 & 0.52 & 13.2 \\
\hline $25 \mathrm{Co}, 0.5 \mathrm{Ru} / \mathrm{N}-\mathrm{GNS}\left(\mathrm{C}_{6}\right)$ & 24.91 & 0.5 & 141 & 0.62 & 0.56 & 9.6 \\
\hline $25 \mathrm{Co}, 0.5 \mathrm{Ru} / \mathrm{PGNS}\left(\mathrm{C}_{7}\right)$ & 24.88 & 0.5 & 129 & 0.59 & 0.55 & 12.1 \\
\hline
\end{tabular}
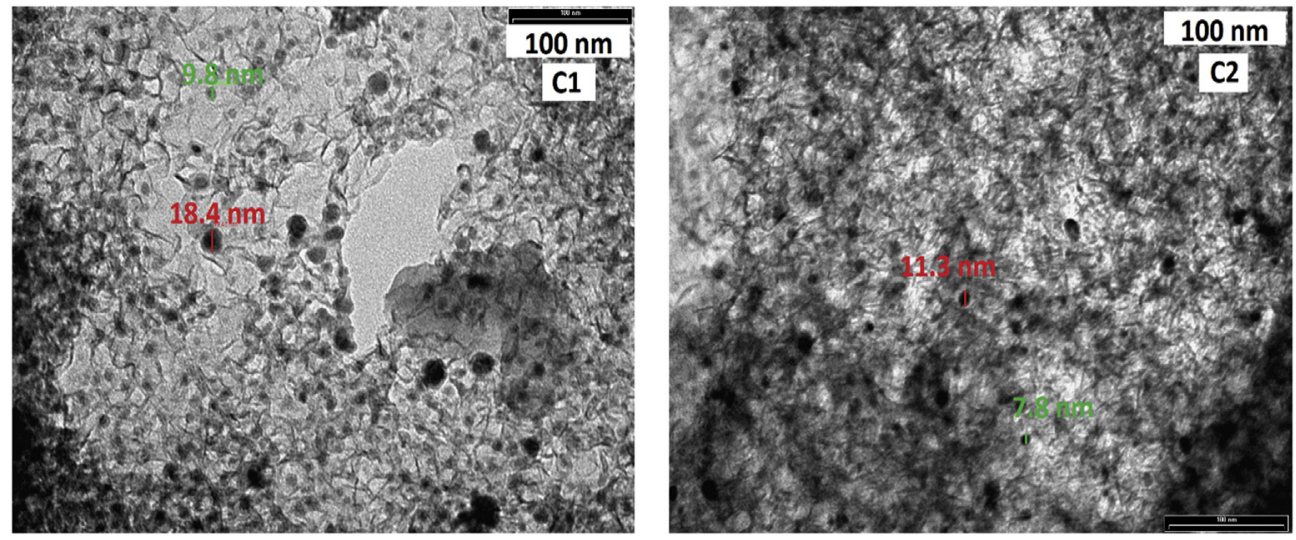

Fig. 7 - TEM image of $C_{1}$ and $C_{2}$ catalysts.

enhancement of the number of cobalt particles which in turn led to an increase in cobalt dispersion in the catalysts [8].

Fig. 9 shows the TPR profiles for all catalysts. There are two peaks for all catalysts. The low temperature peak is attributed to the reduction of $\mathrm{Co}_{3} \mathrm{O}_{4}$ to $\mathrm{CoO}$ and the second peak is attributed to the reduction of $\mathrm{CoO}$ to $\mathrm{Co}^{0}$ species [30]. As shown in Fig. 9, in the case of $C_{1}, C_{7}$ and $C_{2}, C_{6}$ catalysts functionalization of support resulted in shifting the reduction peaks to lower temperature and thus increasing the reducibility of the catalyst. The reason for higher reducibility of $\mathrm{C}_{2}$ catalyst is the confinement phenomenon and hydrogen spillover of functional groups [12]. Fig. 9 also shows increasing the cobalt loading $\left(C_{2}\right.$ to $\left.C_{5}\right)$ decreases the reduction temperature of both TPR profile. This can confirm that by increasing the cobalt loading, the amount of the species reduced at high temperatures decreases. This could suggest an easier reduction for the higher loaded catalysts. Addition of cobalt loading from 15 to $30 \mathrm{wt} \%$ results in a decrease in the temperature of the first TPR peak from 318 to $302{ }^{\circ} \mathrm{C}$ and the temperature of the second TPR peak from 471 to $419^{\circ} \mathrm{C}$. These differences are attributed to the increase in the average cluster size (Table 2) which leads to lower interaction with the support [31]. For the $\mathrm{C}_{6}$ catalyst, Small amounts of $\mathrm{Ru}(0.5 \mathrm{wt} \%)$ facilitate both steps of cobalt oxide reduction. Addition of $0.5 \mathrm{wt} \% \mathrm{Ru}$ to the $\mathrm{C}_{4}$ catalyst results in a decrease in the temperature of the first TPR peak from 307 to $290^{\circ} \mathrm{C}$ and that of the second TPR peak from 423 to $412{ }^{\circ} \mathrm{C}$. It has been proposed that noble metal activates hydrogen and thereby becomes a source for hydrogen spillover to $\mathrm{Co}_{3} \mathrm{O}_{4}$, thus promotes its reduction at lower temperatures. This could lead to a higher extent of reduction in the Ru-promoted catalysts $\left(\mathrm{C}_{6}\right)$ after standard reduction treatment compared with unpromoted catalyst $\left(\mathrm{C}_{4}\right)$. Ruthenium may also enhance the reduction of smaller cobalt species that strongly interacts with support [25-27].

\section{FTS activity and product selectivity}

Table 3 shows the amounts of \%CO conversion, FTS rate, $\mathrm{CO}_{2}$, $\mathrm{CH}_{4}$ and liquid $\mathrm{C}_{5}^{+}$selectivity for all catalysts. According to Table 3, FTS rate and \%Co conversion of the $C_{2}$ and $C_{6}$ catalyst is higher than that of the $C_{1}$ and $C_{7}$ catalyst. The catalyst characterization results showed that the functionalization of PGNS lead to the increase of the catalyst reducibility, the metal dispersion, and the decrease of the average cobalt particle sizes. Due to all these results, the number of surface active cobalt sites increase and consequently the FTS reaction rate and \%Co conversion increase. As shown in Table 3, The FTS rate and \%CO conversion show a remarkable increase with increasing the amount of cobalt loading up to $25 \mathrm{wt} \%$ and then very slightly increases from $25 \mathrm{wt} \%$ to $30 \mathrm{wt} \%$. It is known that the activity of the catalyst in the FTS is commensurate with the number of active cobalt sites which is more at higher cobalt loading. Also, the result of TPR profile showed that increasing cobalt loading enhanced the catalyst reducibility 

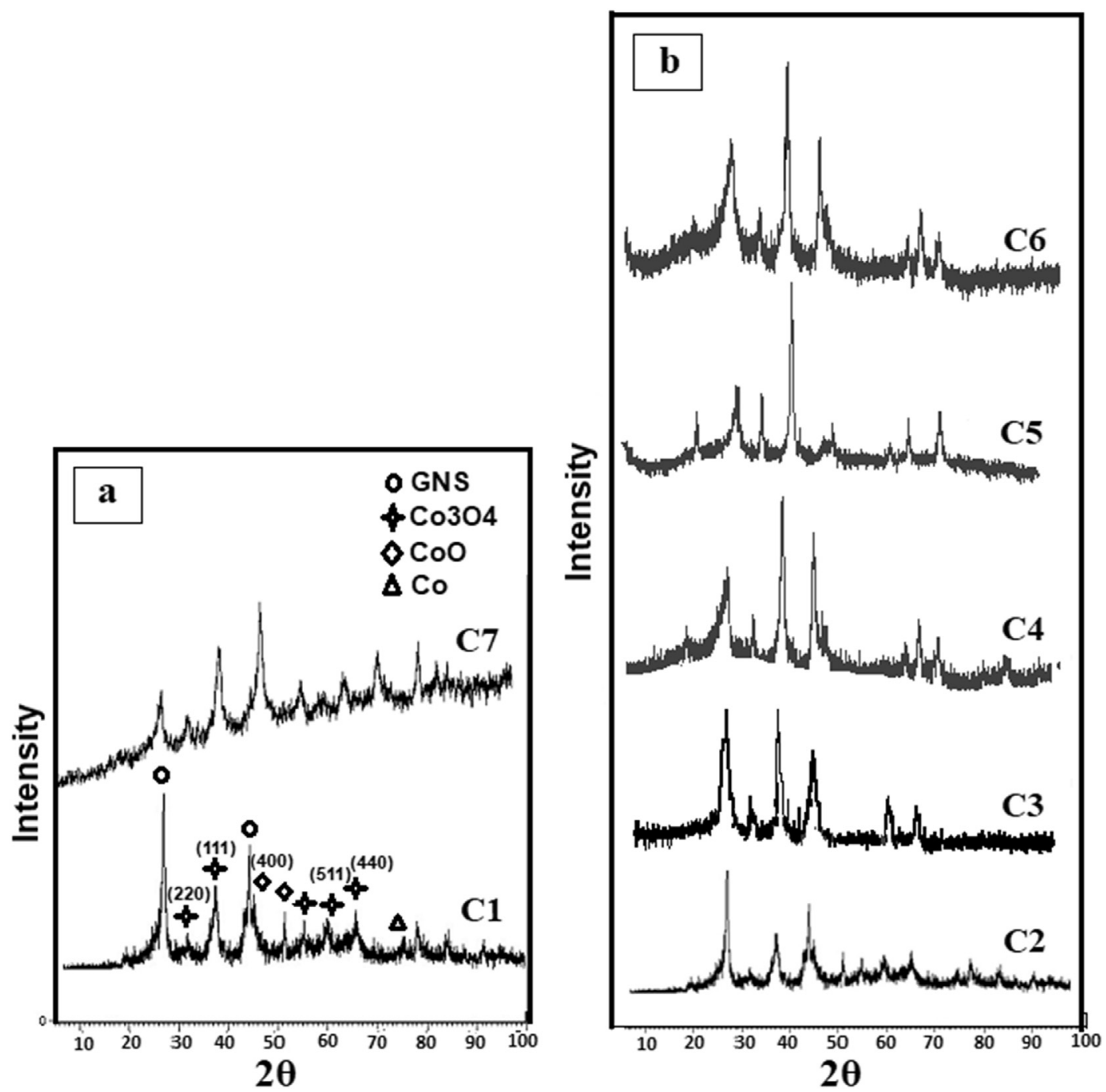

Fig. 8 - XRD patterns of calcined $C_{1}-C_{7}$ catalysts.

and this effect can increase the number of surface active Co metal species and consequently FTS reaction rate. The maximum activity and the maximum concentration of surface $\mathrm{Co}^{\circ}$ sites were obtained at maximum cobalt loading (i.e., $30 \mathrm{wt} \%)[6]$.

Table 3 shows that addition of $\mathrm{Ru}$ to the cobalt catalyst $\left(\mathrm{C}_{6}\right)$ improves \% CO conversion and FTS rate. Ru increased the reduced cobalt surface atoms and the active sites available for FT reaction. The reduction of the ruthenium oxide occurs at lower temperatures than the cobalt oxides. Reduced $\mathrm{Ru}$ ameliorated the reduction of cobalt oxide by increasing hydrogen spillover from $\mathrm{Ru}$ to the cobalt oxide. Moreover, ruthenium can increase the reduction of smaller cobalt oxide particles that may not reduce in the unpromoted catalysts. Thus, $\mathrm{Ru}$ increases the number of active surface $\mathrm{Co}^{\circ}$ sites available for FT reaction and hence enhances the \%CO conversion, and FT reaction rate. It has been reported that addition of $\mathrm{Ru}$ promoter to the cobalt catalysts alters the catalyst morphology. Also, Ru mostly enriches on the surface of cobalt [33]. Considering the higher FTS activity of Ru with respect to cobalt and its enrichment on cobalt surface may be another cause for the activity amelioration in $\mathrm{Ru}$ promoted catalyst [34].

Table 3 reports that methane selectivity increases and liquid $\mathrm{C}_{5}^{+}$selectivity decreases by functionalization of PGNS support. Also, it shows the effect of cobalt loading on the selectivity of Fischer-Tropsch synthesis to $\mathrm{CH}_{4}$ and $\mathrm{C}_{5}^{+}$products for N-GNS supported cobalt catalysts. It clearly shows that the methane selectivity reduces and the selectivity of $\mathrm{C}_{5}^{+}$ increases by increasing the cobalt loading. The results display that the larger cobalt particles are more selective to higher molecular weight hydrocarbons and the smaller particles are more selective for methane [23-29]. Since the addition of cobalt loading from $25 \mathrm{wt} \%$ ( $\mathrm{C}_{4}$ catalyst) to $30 \mathrm{wt} \%$ ( $\mathrm{C}_{5}$ catalyst) did not increase the \%CO conversion and FTS rate significantly, 25 wt\% cobalt loading was selected as the optimum loading and this catalyst was promoted with ruthenium.

Table 3 shows that the methane selectivity decreases and the selectivity of $\mathrm{C}_{5}^{+}$liquid hydrocarbons increases by promoting the cobalt catalyst with Ru. Ruthenium itself is highly selective for the higher molecular weight hydrocarbons than cobalt. Therefore, the amelioration in $\mathrm{C}_{5}^{+}$selectivity observed 

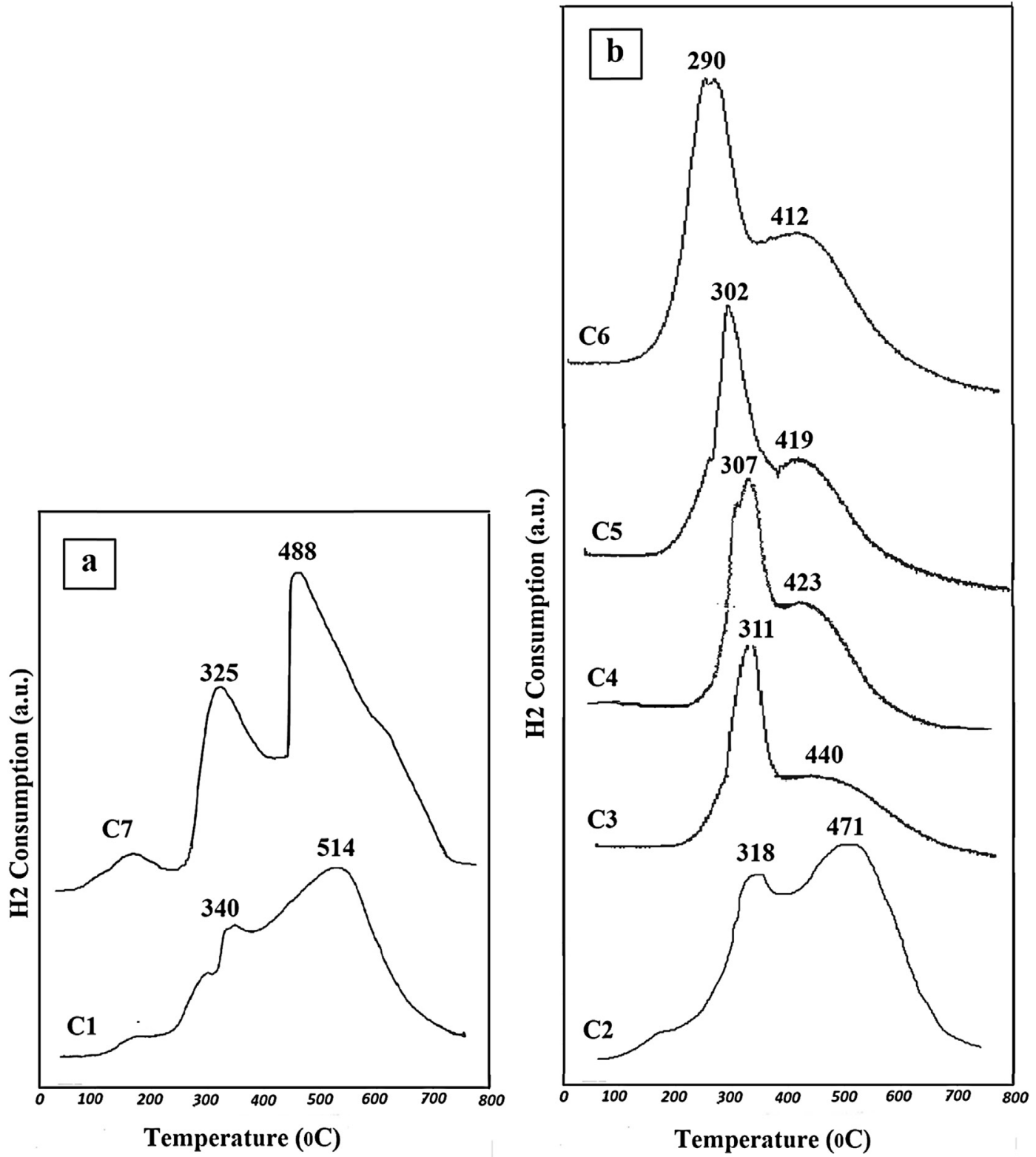

Fig. 9 - TPR of catalysts from 30 to $800{ }^{\circ} \mathrm{C}$.

for Ru promoted catalyst may be owing to the Ru enrichment on the cobalt crystallite surface $[35,36]$.

The selectivity of $\mathrm{CO}_{2}$ over the catalysts is very low. This is mainly because the relatively low reaction temperature can effectively suppress the WGS reaction. Meanwhile, from the literature, graphene as the catalyst support for FTS can also be conducive to reduce WGS activity even at higher temperature [37]. Moreover, the difference of selectivity of $\mathrm{CO}_{2}$ for different catalysts are not very obvious. The small difference of $\mathrm{CO}_{2}$ selectivity among catalysts are related to FTS and WGS reaction rates. Based on equations (5) and (6), it is clear that by increasing FTS rate, the selectivity of $\mathrm{H}_{2} \mathrm{O}$ is

\section{Table 3 - Activity and Products selectivity of catalysts $\left(\mathrm{T}=220^{\circ} \mathrm{C}, \mathrm{H} 2 / \mathrm{CO}\right.$ ratio $=2, \mathrm{P}=1.8 \mathrm{MPa}$ ).}

\begin{tabular}{lccccc} 
Catalyst & CO conversion (\%) & FTS rate $(\mathrm{gCH} /(\mathrm{gcat} \cdot \mathrm{h}))$ & $\%_{\mathrm{CO}_{2}}$ Selectivity & $\% \mathrm{CH}_{4}$ Selectivity & $\% \mathrm{C}_{5}^{+}$Selectivity \\
\hline $\mathrm{C}_{1}$ & 70.6 & 0.325 & 0.43 & 12.3 & 8.3 \\
$\mathrm{C}_{2}$ & 74.5 & 0.354 & 0.54 & 15.3 & 83.8 \\
$\mathrm{C}_{3}$ & 76.4 & 0.365 & 0.62 & 13.7 & 84.7 \\
$\mathrm{C}_{4}$ & 78.6 & 0.377 & 0.75 & 10.9 & 8.7 \\
$\mathrm{C}_{5}$ & 79.1 & 0.382 & 0.76 & 7.7 & 87.2 \\
$\mathrm{C}_{6}$ & 86.9 & 0.412 & 0.80 & 5.8 & 91.2 \\
$\mathrm{C}_{7}$ & 79.2 & 0.353 & 1.0 & & 93.2 \\
\hline
\end{tabular}




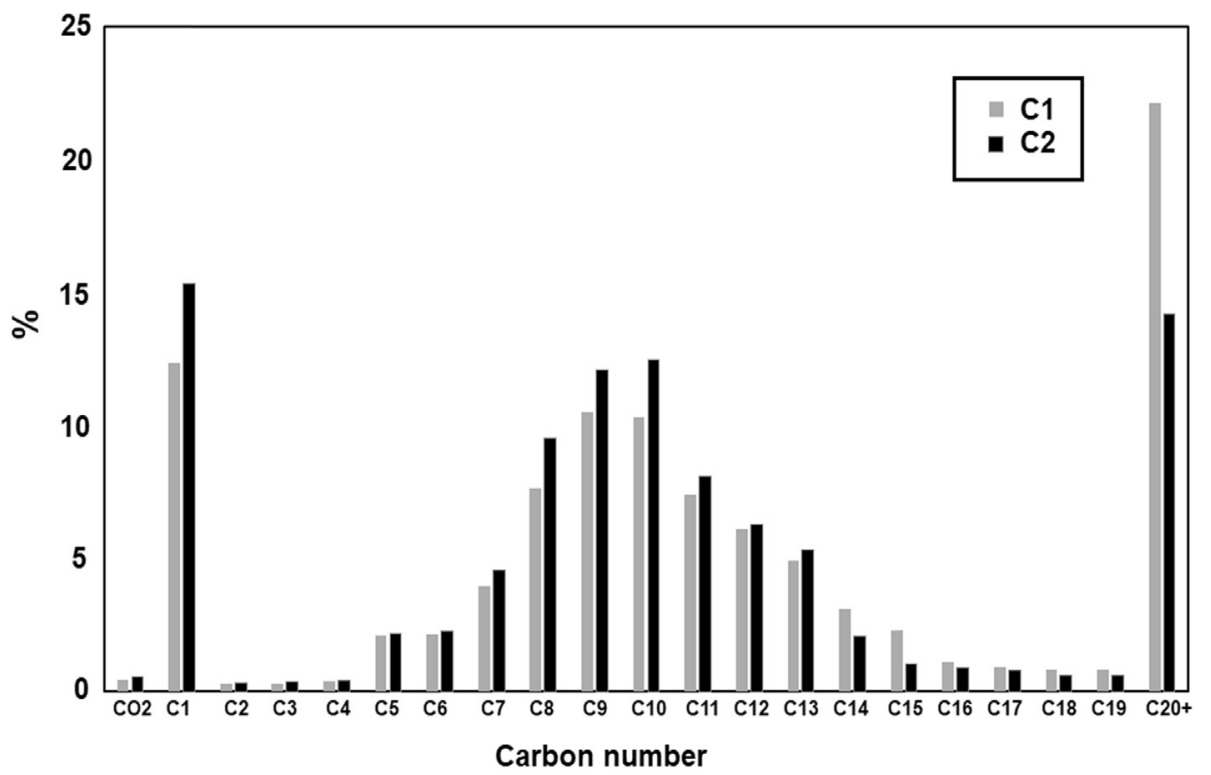

Fig. 10 - Product selectivity for $C_{1}$ and $C_{2}$ catalysts.

increased which leads to an increase in WGS reaction rate and then $\mathrm{CO}_{2}$ selectivity.

Figs. 10 and 11 present the hydrocarbon products distribution for $C_{1}, C_{2}, C_{4}$ and $C_{6}$ catalysts. As shown in Fig. 10, functionalization of PGNS results in a decline in liquid $\mathrm{C}_{5}^{+}$ selectivity. As mentioned earlier, the number of hydrogen adsorbed on the surface of catalyst will be skyrocketed by introducing functional groups to the PGNS which in turn leads to the enhancement of the termination reactions to paraffin rather than chain growth to larger hydrocarbons [12].

Sherif et al. reported a high catalyst activity and $\mathrm{C}_{8}^{+}$selectivity (66.5\%) for $15 \mathrm{wt} \%$ Fe catalyst supported on reduced graphene oxide. However, $15 \mathrm{wt} \%$ Co catalyst supported on PGNS have shown a higher activity and selectivity of $\mathrm{C}_{8}^{+}(78 \%)$ in the present work. The higher activity of the graphenesupported Co catalyst may have been associated with welldispersed nanoparticles on the large surface area of graphene and with enhanced catalyst-graphene interactions attributed to the presence of defect sites that anchor the nanoparticles to the graphene surface. In addition, Further maximization of the $\mathrm{C}_{8}^{+}$hydrocarbons are associated with the nature of Co active metal which is more selective to higher molecular weight hydrocarbons than Fe active metal [38-40].

In addition, Fig. 11 shows that The product distribution shifts to higher molecular weight hydrocarbons with addition of $\mathrm{Ru}$ promoter to the $\mathrm{C}_{4}$ catalyst. $\mathrm{Ru}$ is more selective towards heavier hydrocarbons than cobalt. Thus, due to the $\mathrm{Ru}$ enrichment on the cobalt crystallite surface of $C_{6}$ catalyst, the

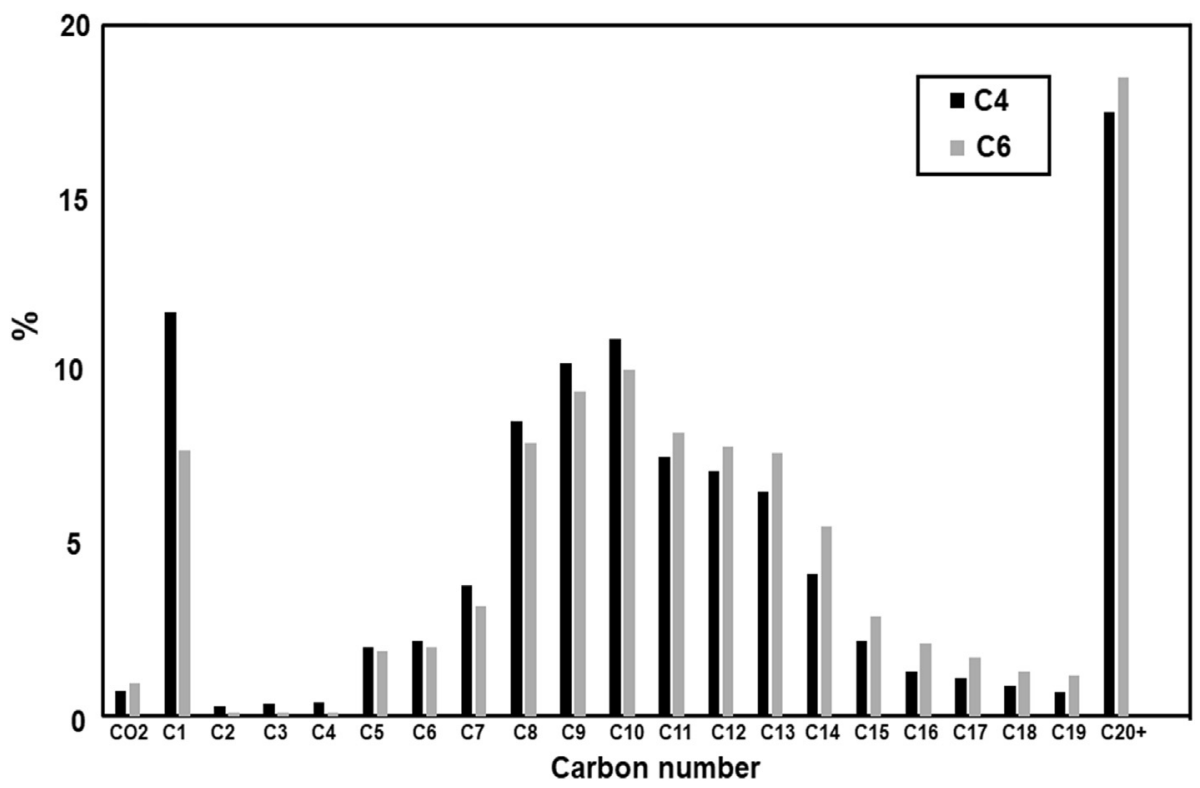

Fig. 11 - Product selectivity for $C_{4}$ and $C_{6}$ catalysts. 
selectivity of heavier liquid products experienced an increase compared to $\mathrm{C}_{4}$ catalyst $[31,32]$.

\section{Conclusion}

PGNS and N-GNS supported cobalt catalysts were prepared via impregnation technique. PGNS Functionalization improved the catalyst activity. TPR results showed that, by increasing the cobalt loading on the N-GNS, the reduction steps shifted to lower temperatures and the reducibility of the catalysts was improved significantly. The catalyst FTS activity is directly proportional to the amount of reduced surface cobalt metal sites. Hence, the activity of catalyst and the $\mathrm{C}_{5}^{+}$selectivity increased and the methane selectivity decreased by increasing the cobalt loading of the catalysts. $\mathrm{Ru}$ promoter enhanced the reducibility, increased the dispersion, increased the FTS rate and enhanced the selectivity of FTS towards the higher molecular weight hydrocarbons. This new catalyst preparation method may offer an attractive alternative for nanoparticles synthesis with uniform and various size distributions for fundamental catalytic studies especially such for structure sensitive FTS catalysis.

\section{R E F E R E N C E S}

[1] James OO, Mesubi AM, Ako TC, Maity S. Increasing carbon utilization in Fischer-Tropsch synthesis using $\mathrm{H}_{2}$-deficient or $\mathrm{CO}_{2}$-rich syngas feeds. Fuel Process Technol 2010;91:136-44. https://doi.org/10.1016/j.fuproc.2009.09.017.

[2] Nguyen N, Yegiyants S, Kaloostian C, Abbas MA, DiFronzo LA. The Surgical Care Improvement Project (SCIP) initiative to reduce infection in elective colorectal surgery: which performance measures affect outcome? Am Surg 2008;74:1012-6. https://doi.org/10.1002/jctb.527.

[3] Wang J, Wang J, Huang X, Chen C, Ma Z, Jia L, et al. Co-Al spinel oxide modified ordered mesoporous alumina supported cobalt-based catalysts for Fischer-Tropsch synthesis. Int J Hydrogen Energy 2018;43:13122-32. https:// doi.org/10.1016/j.ijhydene.2018.04.093.

[4] Jacobs G, Patterson PM, Zhang Y, Das T, Li J, Davis BH. Fischer-Tropsch synthesis: deactivation of noble metalpromoted $\mathrm{Co} / \mathrm{Al}_{2} \mathrm{O}_{3}$ catalysts. Appl Catal Gen 2002;233:215-26. https://doi.org/10.1016/S0926-860X(02) 00147-3.

[5] Khodakov AY, Chu W, Fongarland P. Advances in the development of novel cobalt fischer-tropsch.pdf. Chem Rev 2007;107:1692-744. https://doi.org/10.1021/cr050972v.

[6] Tavasoli A, Abbaslou RMM, Trepanier M, Dalai AK. FischerTropsch synthesis over cobalt catalyst supported on carbon nanotubes in a slurry reactor. Appl Catal Gen 2008;345:134-42. https://doi.org/10.1016/j.apcata.2008.04.030.

[7] Tavasoli A, Sadagiani K, Khorashe F, Seifkordi AA, Rohani AA, Nakhaeipour A. Cobalt supported on carbon nanotubes - a promising novel Fischer-Tropsch synthesis catalyst. Fuel Process Technol 2008;89:491-8. https://doi.org/ 10.1016/j.fuproc.2007.09.008.

[8] Albero J, Garcia H. Journal of molecular catalysis A: chemical doped graphenes in catalysis. J Mol Catal A Chem 2015;408:296-309. https://doi.org/10.1016/j.molcata. 2015.06.011.
[9] Ribeiro H, Dn V, Ah A. Functionalized graphene process in biotechnology: a brief Landscape. J Nanomed Res 2018;7:20-2. https://doi.org/10.15406/jnmr.2018.07.00171.

[10] Yan Y, Miao J, Yang Z, Xiao FX, Yang H Bin, Liu B, et al. Carbon nanotube catalysts: recent advances in synthesis, characterization and applications. Chem Soc Rev 2015;44:3295-346. https://doi.org/10.1039/c4cs00492b.

[11] Chernyak SA, Suslova EV, Egorov AV, Maslakov KI, Savilov SV, Lunin VV. Effect of Co crystallinity on Co/CNT catalytic activity in $\mathrm{CO} / \mathrm{CO}_{2}$ hydrogenation and $\mathrm{CO}$ disproportionation. Appl Surf Sci 2016;372:100-7. https:// doi.org/10.1016/j.apsusc.2016.03.052.

[12] Taghavi S, Asghari A, Tavasoli A. Enhancement of performance and stability of Graphene nano sheets supported cobalt catalyst in Fischer-Tropsch synthesis using Graphene functionalization. Chem Eng Res Des 2017;119:198-208. https://doi.org/10.1016/j.cherd.2017. 01.021.

[13] Tavasoli A, Taghavi S, Tabyar S, Karimi S. Enhancement of ruthenium-promoted Co/CNTs nanocatalyst performance using microemulsion technique. Int J Ind Chem 2014;5. https://doi.org/10.1007/s40090-014-0009-5.

[14] Zafari R, Abdouss M, Zamani Y. Application of response surface methodology for the optimization of light olefins production from CO hydrogenation using an efficient catalyst. Fuel 2019;237:1262-73. https://doi.org/10.1016/ j.fuel.2018.10.074.

[15] Bartholomew $\mathrm{CH}$. Chapter 5 recent developments in fischertropsch catalysis. Stud Surf Sci Catal 1991;64:158-224. https://doi.org/10.1016/S0167-2991(08)60947-7.

[16] Jahangiri $H$, Mahmoudi M, LechWyszynski M, Mahmoudi $H$, Tsolakis A, Gu S, et al. A review of Fischer Tropsch synthesis process, mechanism, surface chemistry and catalyst formulation. Biofuels Eng 2018;2:11-31. https://doi.org/ 10.1515/bfuel-2017-0002.

[17] Salimi P, Javadian S, Norouzi O, Gharibi H. Turning an environmental problem into an opportunity: potential use of biochar derived from a harmful marine biomass named Cladophora glomerata as anode electrode for Li-ion batteries. Environ Sci Pollut Res 2017;24:27974-84. https://doi.org/ 10.1007/s11356-017-0181-1.

[18] Chen W, Fan Z, Pan X, Bao X. Effect of confinement in carbon nanotubes on the activity of Fischer-Tropsch iron catalyst. J Am Chem Soc 2008;130:9414-9. https://doi.org/10.1021/ ja8008192.

[19] Hajjar Z, Kazemeini M, Rashidi A, Bazmi M. Graphene based catalysts for deep hydrodesulfurization of naphtha and diesel fuels: a physiochemical study. Fuel 2016;165:468-76. https://doi.org/10.1016/j.fuel.2015.10.040.

[20] Maultzsch J, Reich S, Thomsen C, Webster S, Czerw R, Carroll DL, et al. Raman characterization of boron-doped multiwalled carbon nanotubes. Appl Phys Lett 2002;81:2647-9. https://doi.org/10.1063/1.1512330.

[21] Peng X, Li Y, Zhang G, Zhang F, Fan X. Functionalization of graphene with nitrile groups by cycloaddition of tetracyanoethylene oxide. J Nanomater 2013;2013. https:// doi.org/10.1155/2013/841789.

[22] Baldovino FH, Quitain AT, Dugos NP, Roces SA, Koinuma M, Yuasa $\mathrm{M}$, et al. Synthesis and characterization of nitrogenfunctionalized graphene oxide in high-temperature and high-pressure ammonia. RSC Adv 2016;6:113924-32. https:// doi.org/10.1039/C6RA22885B.

[23] Eluyemi MS, Eleruja MA, Adedeji AV, Olofinjana B, Fasakin O, Akinwunmi OO, et al. Synthesis and characterization of graphene oxide and reduced graphene oxide thin films deposited by spray pyrolysis method. Graphene 2016;05:143-54. https://doi.org/10.4236/ graphene.2016.53012. 
[24] Tung NT, Van Khai T, Jeon M, Lee YJ, Chung H, Bang JH, et al. Preparation and characterization of nanocomposite based on polyaniline and graphene nanosheets. Macromol Res 2011;19:203-8. https://doi.org/10.1007/s13233-011-0216-2.

[25] Sun Q, Kim S. Synthesis of nitrogen-doped graphene supported Pt nanoparticles catalysts and their catalytic activity for fuel cells. Electrochim Acta 2015;153:566-73. https://doi.org/10.1016/j.electacta.2014.11.077.

[26] Pourhosseini SEM, Norouzi O, Naderi HR. Study of micro/ macro ordered porous carbon with olive-shaped structure derived from Cladophora glomerata macroalgae as efficient working electrodes of supercapacitors. Biomass Bioenergy 2017;107:287-98. https://doi.org/10.1016/j.biombioe.2017. 10.025 .

[27] Cahiers L, Commission L. Cahier Page 1 sur Les infractions au 3820/85 en Europe file://C: \Documents and Settings \ Sébastien Grosjean . ACER-6281EFDEF1 \Mes documents \ Cahier 2 . htm PDF created with FinePrint pdfFactory trial version, vol. 233; 2006. p. 1-6. Cahier Les contrôles PD. Europe, www.pdffactory.com.

[28] Tavasoli A, Taghavi S. Performance enhancement of bimetallic Co-Ru/CNTs nano catalysts using microemulsion technique. J Energy Chem 2013;22:747-54. https://doi.org/ 10.1016/S2095-4956(13)60099-6.

[29] Olivo A, Trevisan V, Ghedini E, Pinna F, Bianchi CL, Naldoni A, et al. $\mathrm{CO}_{2}$ photoreduction with water: catalyst and process investigation. J $\mathrm{CO}_{2}$ Util 2015;12:86-94. https:// doi.org/10.1016/j.jcou.2015.06.001.

[30] Das TK, Jacobs G, Patterson PM, Conner WA, Li J, Davis BH. [47] 1-s2.0-S0016236102003617-main.pdf, vol. 82; 2003. p. $805-15$.

[31] Tavasoli A, Sadaghiani K, Nakhaelpour A, Ahangari M. Cobalt loading effects on the structure and activity for fischertropsch and water-gas shift reactions of $\mathrm{Co} / \mathrm{Al}_{2} \mathrm{O}_{3}$ catalysts. Iran J Chem Chem Eng 2007;26:9-16.

[32] Coronel-García MA, Reyes De La Torre AI, Melo-Banda JA, Martínez-Salazar AL, Silva Rodrigo R, Díaz Zavala NP, et al. Study of Co, Ru/SBA-15 type materials for Fischer-Tropsch synthesis in fixed bed tubular reactor: I. Effect of the high Ru content on the catalytic activity. Int J Hydrogen Energy
2015;40:17264-71. https://doi.org/10.1016/

j.ijhydene.2015.09.061.

[33] Romar H, Rivoire E, Tynjälä P, Lassi U. Effect of calcination conditions on the dispersion of cobalt over $\mathrm{Re}, \mathrm{Ru}$ and $\mathrm{Rh}$ promoted $\mathrm{Co} / \gamma-\mathrm{Al}_{2} \mathrm{O}_{3}$ Catalysts. Top Catal 2017;60:1408-14. https://doi.org/10.1007/s11244-017-0822-0.

[34] Haghtalab A, Mosayebi A. Co@Ru nanoparticle with coreshell structure supported over $\gamma-\mathrm{Al}_{2} \mathrm{O}_{3}$ for Fischer-Tropsch synthesis. Int J Hydrogen Energy 2014;39:18882-93. https:// doi.org/10.1016/j.ijhydene.2014.09.074.

[35] Tavasoli A, Karimi A, Khodadadi AA, Mortazavi Y, Mousavian MA. Accelerated deactivation and activity recovery studies of ruthenium and rhenium promoted cobalt catalysts in Fischer-Tropsch synthesis. Iran J Chem Chem Eng 2005;24:25-36.

[36] Trépanier M, Tavasoli A, Dalai AK, Abatzoglou N. Co, Ru and $\mathrm{K}$ loadings effects on the activity and selectivity of carbon nanotubes supported cobalt catalyst in Fischer-Tropsch synthesis. Appl Catal Gen 2009;353:193-202. https://doi.org/ 10.1016/j.apcata.2008.10.061.

[37] Bukur DB, Todic B, Elbashir N. Role of water-gas-shift reaction in Fischer-Tropsch synthesis on iron catalysts: a review. Catal Today 2016;275:66-75. https://doi.org/10.1016/ j.cattod.2015.11.005.

[38] Moussa SO, Panchakarla LS, Ho MQ, El-Shall MS. Graphenesupported, iron-based nanoparticles for catalytic production of liquid hydrocarbons from synthesis gas: the role of the graphene support in comparison with carbon nanotubes. ACS Catal 2014;4:535-45. https://doi.org/10.1021/cs4010198.

[39] Chen Y, Batalha N, Marinova M, Impéror-Clerc M, Ma C, Ersen $\mathrm{O}$, et al. Ruthenium silica nanoreactors with varied metal-wall distance for efficient control of hydrocarbon distribution in Fischer-Tropsch synthesis. J Catal 2018;365:429-39. https://doi.org/10.1016/j.jcat.2018.06.023.

[40] Ribeiro ATS, Bezerra VVL, Bartolomeu RAC, Abreu CAM, Filho NML, Silva AOS, et al. Influence of sucrose addition and acid treatment of silica-supported Co-Ru catalysts for Fischer-Tropsch synthesis. Fuel 2018;231:157-64. https:// doi.org/10.1016/j.fuel.2018.05.064. 